\title{
Fuzzy clustering analysis to study geomagnetic coastal effects
}

\author{
M. Sridharan ${ }^{1}$, N. Gururajan ${ }^{2}$, and A. M. S. Ramasamy ${ }^{3}$ \\ ${ }^{1}$ IIG Magnetic Observatory, Pondicherry University Campus, Pondicherry 605014, India \\ ${ }^{2}$ Department of Mathematics, KM Centre for Post Graduate Studies, Pondicherry University, Pondicherry 605008, India \\ ${ }^{3}$ Department of Mathematics, Pondicherry University, Pondicherry 605014, India
}

Received: 1 April 2004 - Revised: 10 March 2005 - Accepted: 22 March 2005 - Published: 3 June 2005

\begin{abstract}
The utility of fuzzy set theory in cluster analysis and pattern recognition has been evolving since the mid 1960 s, in conjunction with the emergence and evolution of computer technology. The classification of objects into categories is the subject of cluster analysis. The aim of this paper is to employ Fuzzy-clustering technique to examine the interrelationship of geomagnetic coastal and other effects at Indian observatories. Data from the observatories used for the present studies are from Alibag on the West Coast, Visakhapatnam and Pondicherry on the East Coast, Hyderabad and Nagpur as central inland stations which are located far from either of the coasts; all the above stations are free from the influence of the daytime equatorial electrojet. It has been found that Alibag and Pondicherry Observatories form a separate cluster showing anomalous variations in the vertical (Z)-component. H- and D-components form different clusters. The results are compared with the graphical method. Analytical technique and the results of Fuzzyclustering analysis are discussed here.
\end{abstract}

Keywords. Geomagnetism and paleomagnetism (Spatial variations attributed to sea floor spreading; Time variations, secular and long term; General or miscellaneous)

\section{Introduction}

Geomagnetic quiet day $(\mathrm{Sq})$ variations have been widely analyzed by many scientists. There is an obvious annual increase in amplitude during the summer months and a seasonal shift of the maximum early in summer and late in winter for solar quiet day $(\mathrm{Sq})$ variations at middle- and low-latitude stations (Campbell, 1997). It is only approximately true that Sq depends on local time and latitude only. There is a distinct, although small, longitude effect (Parkinson, 1983).

The quiet-day maximum-minimum range in $\mathrm{H}$ (Yacob and Sen, 1974) and "best" estimates of the amplitudes of diurnal and semidiurnal components of $\mathrm{Sq}(\mathrm{H})$ and their annual

Correspondence to: M. Sridharan

(mopondy@sancharnet.in) variations (Rangarajan, 1975), the latitudinal profile over India of $\mathrm{Sq}(\mathrm{H})$ range and of its prominent periodicities (Yacob, 1975), have been studied in detail. Quiet day mean hourly variations of the geomagnetic field have been utilized to study the solar control of the low-latitude quiet day magnetic field (Bhargava and Rangarajan, 1979) and local time and solar cycle features of the day-to-day variability in horizontal intensity (Bhargava and Yacob, 1969 and 1974); in addition, daily variations at low latitudes (Rastogi, 1992) and daily variations at low latitudes associated with stable solar wind flow (Rangarajan, 1981), etc., have been analyzed based on geomagnetic quiet day variations at Indian observatories.

Hence, it is appropriate to take the daily range of the solar quiet day hourly mean values of declination (D), horizontal $(\mathrm{H})$ and vertical $(\mathrm{Z})$ components of the Earth's magnetic field with the available common data for the years 1995, 1996 and 1997, namely $\mathrm{Sq}(\mathrm{D}), \mathrm{Sq}(\mathrm{H}), \mathrm{Sq}(\mathrm{Z})$ on all international quiet days. The results agree with the graphical method found by Srivastava et al. (2001) using 1995 data. The results from the analytic technique of Fuzzy-cluster analysis are highly encouraging for application of this technique to the future analysis of geomagnetic data.

The geographic and dipole coordinates of the observatories are provided in Table 1. From 1995 to 1997 there were 180 international quiet days. Daily ranges, namely the difference between daily maximum and daily minimum on individual days, are calculated, and monthly mean values of the ranges are listed in Table 2. Seasonal variations for the Dseason (December solstice), comprising the months January, February, November and December; E-season (Equinoxial) comprising the months March, April, September and October; and J-season (June solstice), comprising the months May, June, July and August, are found and listed in Table 3. All the above 5 stations' westerly declination in minutes of arc have been converted to variations in $\mathrm{nT}$ for uniformity. Seasonal variations for the years 1995, 1996 and 1997 are plotted in Figs. 1, 2 and 3. 
Table 1. Locations of Observatories.

\begin{tabular}{lll}
\hline Station & Geographic & Dipole \\
\hline 1. Alibag(ALI) & Latitude $18^{\circ} 37^{\prime} \mathrm{N}$ & $9.7^{\circ} \mathrm{N}$ \\
& Longitude $72^{\circ} 52^{\prime} \mathrm{E}$ & $145.6^{\circ}$ \\
\hline 2.Hyderabad(HYD) & Latitude $17^{\circ} 25^{\prime} \mathrm{N}$ & $7.6^{\circ} \mathrm{N}$ \\
& Longitude $78^{\circ} 33^{\prime} \mathrm{E}$ & $148.9^{\circ}$ \\
\hline 3. Nagpur(NAG) & Latitude $21^{\circ} 09^{\prime} \mathrm{N}$ & $11.7^{\circ} \mathrm{N}$ \\
& Longitude $79^{\circ} 05^{\prime} \mathrm{E}$ & $151.9^{\circ}$ \\
\hline 4. Pondicherry(PON) & Latitude $11^{\circ} 55^{\prime} \mathrm{N}$ & $2.4^{\circ} \mathrm{N}$ \\
& Longitude $79^{\circ} 55^{\prime} \mathrm{E}$ & $151.7^{\circ}$ \\
\hline 5. Visakhapatnam(VIZ) & Latitude $17^{\circ} 41^{\prime} \mathrm{N}$ & $07.8^{\circ} \mathrm{N}$ \\
& Longitude $83^{\circ} 19^{\prime} \mathrm{E}$ & $155.8^{\circ}$ \\
\hline
\end{tabular}

\section{Concept of fuzzy clustering}

The method of fuzzy clustering is based on a fuzzy equivalence relation (Klir and Yuvan, 1997). An equivalence relation is a relation defined on a set which is reflexive, symmetric and transitive, whereas a fuzzy equivalence relation is a relation defined on a set which is reflexive, symmetric, and max-min transitive. Like an ordinary equivalence relation, a fuzzy equivalence relation also induces a partition in each of its $\alpha$-cuts (Zadeh, 1965). The fuzzy clustering problem can thus be viewed as the problem of identifying an appropriate fuzzy compatibility relation in terms of an appropriate distance function applied to given data (Klir and Folger, 2000). Then a meaningful fuzzy equivalence relation is defined based on the transitive closure of the fuzzy compatibility relation (Anderberg, 1973).

\section{Method of fuzzy clustering}

Suppose $\mathrm{S}$ is a set consisting of $\mathrm{n}$ data items. Let $\mathrm{R}$ be the set of all real numbers. Let $p$ be a natural number. Suppose each data item in $\mathrm{S}$ is a p-tuple in $\mathrm{R}^{\mathrm{p}}$. Consider any two points $\mathrm{X}_{\mathrm{i}}$ $\mathrm{X}_{\mathrm{k}}$ in $\mathrm{S}$ with

$\mathrm{X}_{\mathrm{i},}=\left(\mathrm{x}_{\mathrm{i} 1}, \mathrm{x}_{\mathrm{i} 2}, \mathrm{x}_{\mathrm{i} 3}, \ldots, \mathrm{x}_{\mathrm{ip}}\right)$

$\mathrm{X}_{\mathrm{k}}=\left(\mathrm{x}_{\mathrm{k} 1}, \mathrm{x}_{\mathrm{k} 2}, \mathrm{x}_{\mathrm{k} 3} \ldots \ldots, \mathrm{x}_{\mathrm{kp}}\right)$.

Let a fuzzy compatibility relation $\mathrm{R}$ on $\mathrm{S}$ be defined in terms of an appropriate distance function of the Minkowski class by the formula

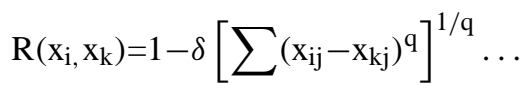

For all pairs $\left(\mathrm{x}_{\mathrm{i}}, \mathrm{x}_{\mathrm{k}}\right) \in \mathrm{S}$ where $\mathrm{q}$ is a positive real number and $\delta$ is a constant that ensures that $\mathrm{R}\left(\mathrm{x}_{\mathrm{i}}, \mathrm{x}_{\mathrm{k}}\right) \in[0,1]$. The quantity $\delta$ is the inverse value of the largest distance in $\mathrm{S}$.

In general, R, defined by Eq. (1) is a fuzzy compatibility relation and it need not be a fuzzy equivalence relation. An algorithm is required to determine the transitive closure of $\mathrm{R}$. Since $\mathrm{R}$ is a compatibility relation, one can use the following result in the formulation of an algorithm.

\section{Result on max-min transitive closure}

Let $\mathrm{S}$ be a finite universal set. Let the number of elements in $\mathrm{S}$ be $\mathrm{n}$. Let $\mathrm{R}$ be a fuzzy compatibility relation on $\mathrm{S}$. Then the max-min transitive closure of $\mathrm{R}$ is the relation $\mathrm{R}^{(\mathrm{n}-1)}$.

\section{Transitive closure algorithm}

Let $\mathrm{R}$ be a square matrix of order $\mathrm{k}$ obtained from the given data matrix by employing Eq. (1):

Take $\mathrm{R}^{(2)}=$ Ro R...,

where an element of $R$ o $R$ is max-min $\left(X_{r j}, X_{j s}\right)$ with $j$ varying from 1 to $\mathrm{k}$, where $X_{\mathrm{rs}}$ is an element in the $\mathrm{r}^{\text {th }}$ row and $\mathrm{s}^{\text {th }}$ column of the matrix $R^{(2)}$.

Similarly,

$\mathrm{R}^{(4)}=\mathrm{R}^{(2)} \mathrm{o} \mathrm{R}^{(2)} \ldots$

.............

$\mathrm{R}^{(2 \mathrm{k})}=\mathrm{R}^{(2 \mathrm{k}-1)} \mathrm{OR}(2 \mathrm{k}-1) \ldots$

This is continued until no new relation is produced. Thus, the max-min transitive closure of $R$ is the relation $R^{(n-k)}$ which is denoted by $R \tau$. Finally this relation induces partitions called $\alpha$-cuts in different intervals. The partitions agree with the visual perception of geometric clusters in the data.

\section{Application of fuzzy clustering to geomagnetic Sq variations}

The monthly mean values of the $\mathrm{Sq}$ range for the $\mathrm{D}, \mathrm{H}$, $\mathrm{Z}$ components for the 36 months from Table 2 are considered. From this table a distance matrix is obtained with the formula Distance $=$ square root of $\left[\left(\mathrm{x}_{11}-\mathrm{x}_{12}\right)^{2}+\left(\mathrm{x}_{21}-\mathrm{x}_{22}\right)^{2}\right.$ $\left.+\ldots \ldots+\left(\mathrm{x}_{n 1}-\mathrm{x}_{n 2}\right)^{2}\right]$ etc ... for Euclidean distance. It is given as the distance matrix for each component.

The declination (D)-component will be used to explain the analysis and is applicable to horizontal $(\mathrm{H})$ - and vertical (Z)-components.

Abbreviations:
Alibag:
ALB
Hyderabad:
HYD
Nagpur:
NAG
Pondicherry: PON
Visakhapatnam: VIZ

Euclidean distance matrix for declination component-D:

$\left.\begin{array}{l|rrrrr}\multicolumn{1}{c}{\text { ALB }} & \text { HYD } & \text { NAG } & \text { PON } & \multicolumn{1}{l}{\text { VIZ }} \\ \text { ALB } & 0 & 16.97 & 23.98 & 31.03 & 30.397 \\ \text { HYD } & 16.97 & 0 & 17.17 & 29.65 & 18.38 \\ \text { NAG } & 23.98 & 17.17 & 0 & 25.14 & 26.32 \\ \text { PON } & 31.03 & 29.65 & 25.14 & 0 & 42.77 \\ \text { VIZ } & 30.397 & 18.38 & 26.32 & 42.77 & 0\end{array}\right)$


Table 2. Monthly variations for the components D, H and Z for the years 1995, 1996 and 1997 in nT.

\begin{tabular}{|c|c|c|c|c|c|c|c|c|c|c|c|c|c|c|c|}
\hline YEAR & $\begin{array}{c}\text { ALB- } \\
\text { D }\end{array}$ & $\begin{array}{c}\text { HYD- } \\
\text { D }\end{array}$ & $\begin{array}{c}\text { NAG- } \\
\text { D }\end{array}$ & $\begin{array}{c}\text { PON- } \\
\text { D }\end{array}$ & $\begin{array}{c}\text { VIZ- } \\
\text { D }\end{array}$ & $\begin{array}{c}\text { ALB- } \\
\mathrm{H}\end{array}$ & $\begin{array}{c}\text { HYD- } \\
\text { D }\end{array}$ & $\begin{array}{c}\text { NAG- } \\
\mathrm{H}\end{array}$ & $\begin{array}{c}\text { PON- } \\
\mathrm{H}\end{array}$ & $\begin{array}{c}\text { VIZ- } \\
\mathrm{H}\end{array}$ & $\begin{array}{c}\text { ALI- } \\
\text { Z }\end{array}$ & $\begin{array}{c}\text { HYD- } \\
\text { D }\end{array}$ & $\begin{array}{c}\text { NAG- } \\
Z\end{array}$ & $\begin{array}{c}\text { PON- } \\
\text { Z }\end{array}$ & $\begin{array}{c}\text { VIZ- } \\
\text { Z }\end{array}$ \\
\hline 95Jan & 22 & 26 & 29 & 28 & 28 & 20 & 23 & 29 & 35 & 23 & 18 & 15 & 13 & 26 & 17 \\
\hline Feb & 15 & 17 & 20 & 19 & 18 & 35 & 37 & 49 & 36 & 34 & 15 & 12 & 11 & 24 & 15 \\
\hline Mar & 30 & 29 & 34 & 27 & 31 & 49 & 54 & 61 & 69 & 55 & 22 & 21 & 20 & 40 & 24 \\
\hline Apr & 42 & 45 & 44 & 38 & 50 & 42 & 49 & 54 & 69 & 55 & 32 & 26 & 25 & 35 & 23 \\
\hline May & 48 & 50 & 49 & 44 & 53 & 36 & 42 & 48 & 51 & 39 & 30 & 22 & 18 & 31 & 15 \\
\hline Jun & 59 & 62 & 61 & 51 & 63 & 44 & 49 & 57 & 50 & 45 & 37 & 20 & 21 & 25 & 14 \\
\hline Jul & 51 & 53 & 54 & 43 & 61 & 46 & 50 & 56 & 56 & 45 & 33 & 26 & 24 & 25 & 15 \\
\hline Aug & 54 & 50 & 48 & 43 & 52 & 41 & 43 & 54 & 51 & 41 & 31 & 29 & 25 & 32 & 21 \\
\hline Sep & 51 & 52 & 49 & 47 & 54 & 32 & 36 & 46 & 46 & 33 & 32 & 26 & 21 & 28 & 15 \\
\hline Oct & 22 & 22 & 23 & 21 & 24 & 38 & 42 & 51 & 53 & 42 & 18 & 18 & 11 & 21 & 13 \\
\hline Nov & 16 & 18 & 19 & 17 & 20 & 35 & 39 & 49 & 46 & 41 & 16 & 15 & 10 & 21 & 13 \\
\hline Dec & 17 & 24 & 26 & 22 & 26 & 25 & 29 & 38 & 31 & 29 & 15 & 14 & 14 & 25 & 14 \\
\hline 96Jan & 22 & 18 & 27 & 24 & 24 & 31 & 33 & 40 & 43 & 33 & 23 & 17 & 23 & 26 & 19 \\
\hline Feb & 23 & 21 & 27 & 29 & 21 & 40 & 44 & 51 & 50 & 45 & 16 & 11 & 13 & 19 & 13 \\
\hline Mar & 15 & 16 & 21 & 21 & 21 & 38 & 41 & 50 & 48 & 43 & 15 & 11 & 12 & 22 & 12 \\
\hline Apr & 42 & 40 & 41 & 41 & 51 & 42 & 52 & 56 & 65 & 51 & 30 & 21 & 23 & 30 & 22 \\
\hline May & 45 & 41 & 43 & 41 & 51 & 42 & 50 & 55 & 53 & 44 & 29 & 14 & 20 & 22 & 17 \\
\hline Jun & 47 & 39 & 43 & 38 & 48 & 42 & 46 & 55 & 45 & 42 & 27 & 14 & 17 & 21 & 13 \\
\hline Jul & 33 & 31 & 33 & 30 & 39 & 29 & 31 & 40 & 39 & 28 & 26 & 19 & 18 & 24 & 14 \\
\hline Aug & 53 & 41 & 44 & 44 & 49 & 25 & 28 & 42 & 40 & 25 & 31 & 21 & 21 & 30 & 17 \\
\hline Sep & 51 & 48 & 51 & 52 & 57 & 38 & 46 & 55 & 59 & 41 & 35 & 24 & 22 & 28 & 19 \\
\hline Oct & 32 & 29 & 31 & 28 & 33 & 40 & 47 & 52 & 54 & 46 & 23 & 13 & 19 & 23 & 17 \\
\hline Nov & 15 & 15 & 16 & 16 & 15 & 42 & 46 & 55 & 48 & 43 & 15 & 7 & 8 & 21 & 13 \\
\hline Dec & 17 & 15 & 20 & 19 & 17 & 28 & 30 & 40 & 35 & 29 & 12 & 9 & 9 & 18 & 13 \\
\hline 97Jan & 24 & 22 & 27 & 23 & 26 & 25 & 27 & 38 & 34 & 25 & 23 & 15 & 15 & 21 & 14 \\
\hline Feb & 19 & 18 & 27 & 23 & 25 & 36 & 39 & 47 & 43 & 37 & 13 & 10 & 11 & 17 & 14 \\
\hline Mar & 32 & 26 & 32 & 26 & 30 & 47 & 52 & 58 & 58 & 50 & 22 & 14 & 15 & 24 & 14 \\
\hline Apr & 37 & 36 & 39 & 36 & 44 & 32 & 37 & 45 & 51 & 35 & 28 & 19 & 17 & 31 & 15 \\
\hline May & 38 & 34 & 38 & 34 & 39 & 35 & 38 & 47 & 47 & 36 & 37 & 13 & 13 & 29 & 14 \\
\hline Jun & 38 & 37 & 40 & 34 & 45 & 39 & 43 & 50 & 49 & 43 & 26 & 17 & 19 & 26 & 18 \\
\hline Jul & 38 & 36 & 40 & 35 & 36 & 39 & 41 & 51 & 40 & 39 & 22 & 9 & 11 & 15 & 9 \\
\hline Aug & 45 & 44 & 46 & 46 & 49 & 40 & 45 & 55 & 48 & 40 & 30 & 18 & 19 & 22 & 15 \\
\hline Sep & 45 & 46 & 50 & 48 & 56 & 39 & 46 & 54 & 60 & 44 & 36 & 22 & 22 & 37 & 22 \\
\hline Oct & 26 & 30 & 33 & 29 & 39 & 34 & 41 & 46 & 62 & 42 & 31 & 23 & 21 & 42 & 23 \\
\hline Nov & 18 & 18 & 22 & 19 & 20 & 33 & 43 & 46 & 45 & 39 & 15 & 11 & 13 & 25 & 13 \\
\hline Dec & 19 & 22 & 24 & 25 & 29 & 21 & 23 & 32 & 32 & 23 & 24 & 16 & 19 & 23 & 16 \\
\hline
\end{tabular}

Relational matrix $\mathrm{R}$ arising from the Euclidean distance equation for the element $\mathrm{D}$ is

$\mathrm{R}=$
Next $\mathbf{R}^{(2)}$ is obtained using the transitive closure algorithm described above. The result is given below:

$\mathrm{R}^{(2)}=\mathrm{R}$ o $\mathrm{R}=$

\begin{tabular}{|c|c|c|c|c|c|c|c|c|c|c|c|}
\hline & ALB & HYD & NAG & PON & VIZ & & ALB & HYD & NAG & PON & VIZ \\
\hline ALB & 1 & 0.60323 & 0.43933 & 0.27449 & $0.28929)$ & ALB & 1 & 0.60323 & 0.59855 & 0.41220 & $0.57026)$ \\
\hline HYD & 0.60323 & 1 & 0.59855 & 0.30676 & 0.57026 & HYD & 0.60323 & 1 & 0.59855 & 0.41220 & 0.57026 \\
\hline NAG & 0.43933 & 0.59855 & 1 & 0.41220 & 0.38462 & NAG & 0.59855 & 0.59855 & 1 & 0.41220 & 0.57026 \\
\hline PON & 0.27449 & 0.30676 & 0.41220 & 1 & 0 & PON & 0.41220 & 0.41220 & 0.41220 & 1 & 0.38462 \\
\hline VIZ & 0.28929 & 0.57026 & 0.38462 & 0 & 1 & VIZ & 0.57026 & 0.57026 & 0.57026 & 0.38462 & 1 \\
\hline
\end{tabular}


Table 3. Seasonal variations for $\mathrm{D}, \mathrm{H}$ and $\mathrm{ZnT}$.

\begin{tabular}{|c|c|c|c|c|c|c|c|c|c|c|c|c|c|c|c|}
\hline YEAR & $\begin{array}{c}\text { ALI- } \\
\text { D }\end{array}$ & $\begin{array}{c}\text { HYD- } \\
\text { D }\end{array}$ & $\begin{array}{c}\text { NAG- } \\
\text { D }\end{array}$ & $\begin{array}{l}\text { PON- } \\
\text { D }\end{array}$ & $\begin{array}{c}\text { VIZ- } \\
\text { D }\end{array}$ & $\begin{array}{c}\text { ALB- } \\
\mathrm{H}\end{array}$ & $\begin{array}{c}\text { HYD- } \\
\text { H }\end{array}$ & $\begin{array}{c}\text { NGP- } \\
\mathrm{H}\end{array}$ & $\begin{array}{c}\text { PON- } \\
\mathrm{H}\end{array}$ & $\begin{array}{c}\text { VIZ- } \\
\mathrm{H}\end{array}$ & $\begin{array}{c}\text { ALB- } \\
Z\end{array}$ & $\begin{array}{c}\text { HYD- } \\
Z\end{array}$ & $\begin{array}{c}\text { NAG- } \\
Z\end{array}$ & $\begin{array}{c}\text { PON- } \\
\text { Z }\end{array}$ & $\begin{array}{c}\text { VIZ- } \\
\text { Z }\end{array}$ \\
\hline 95D & 17.5 & 21.25 & 23.5 & 21.5 & 23 & 28.75 & 32 & 41.25 & 37 & 29.25 & 16 & 14 & 12 & 24 & 15.5 \\
\hline $95 \mathrm{E}$ & 36.25 & 37 & 37.5 & 33.25 & 39.75 & 40.25 & 45.25 & 53 & 59.25 & 46.25 & 26 & 22.75 & 19.25 & 31 & 18.75 \\
\hline $95 \mathrm{~J}$ & 53 & 53.75 & 53 & 45.25 & 57.25 & 41.75 & 46 & 53.75 & 52 & 42.5 & 32.75 & 24.25 & 22 & 28.25 & 16.25 \\
\hline $96 \mathrm{D}$ & 19.25 & 19.75 & 22.5 & 22 & 19.25 & 35.25 & 38.25 & 46.5 & 44 & 37.5 & 16.5 & 11 & 13.25 & 21 & 14.5 \\
\hline $96 \mathrm{E}$ & 35 & 43.75 & 36 & 35.5 & 40.5 & 39.5 & 46.5 & 53.25 & 56.5 & 45.25 & 25.75 & 17.25 & 19 & 25.75 & 17.5 \\
\hline $96 \mathrm{~J}$ & 44.5 & 43.75 & 40.75 & 38.25 & 46.75 & 34.5 & 38.75 & 48 & 44.25 & 34.75 & 28.25 & 17 & 19 & 24.25 & 15.25 \\
\hline 97D & 21 & 23 & 25 & 22.5 & 25 & 28.75 & 33 & 40.75 & 38.5 & 31 & 18.75 & 13 & 14.5 & 21.5 & 14.25 \\
\hline $97 \mathrm{E}$ & 38 & 39.5 & 38.5 & 34.75 & 42.25 & 38 & 44 & 50.75 & 57.75 & 42.75 & 29.25 & 19.5 & 18.75 & 33.5 & 18.5 \\
\hline $97 \mathrm{~J}$ & 44 & 43 & 41 & 37.25 & 43 & 38.25 & 41.75 & 50.75 & 46 & 39.5 & 28.75 & 14.25 & 15.5 & 23 & 14 \\
\hline
\end{tabular}
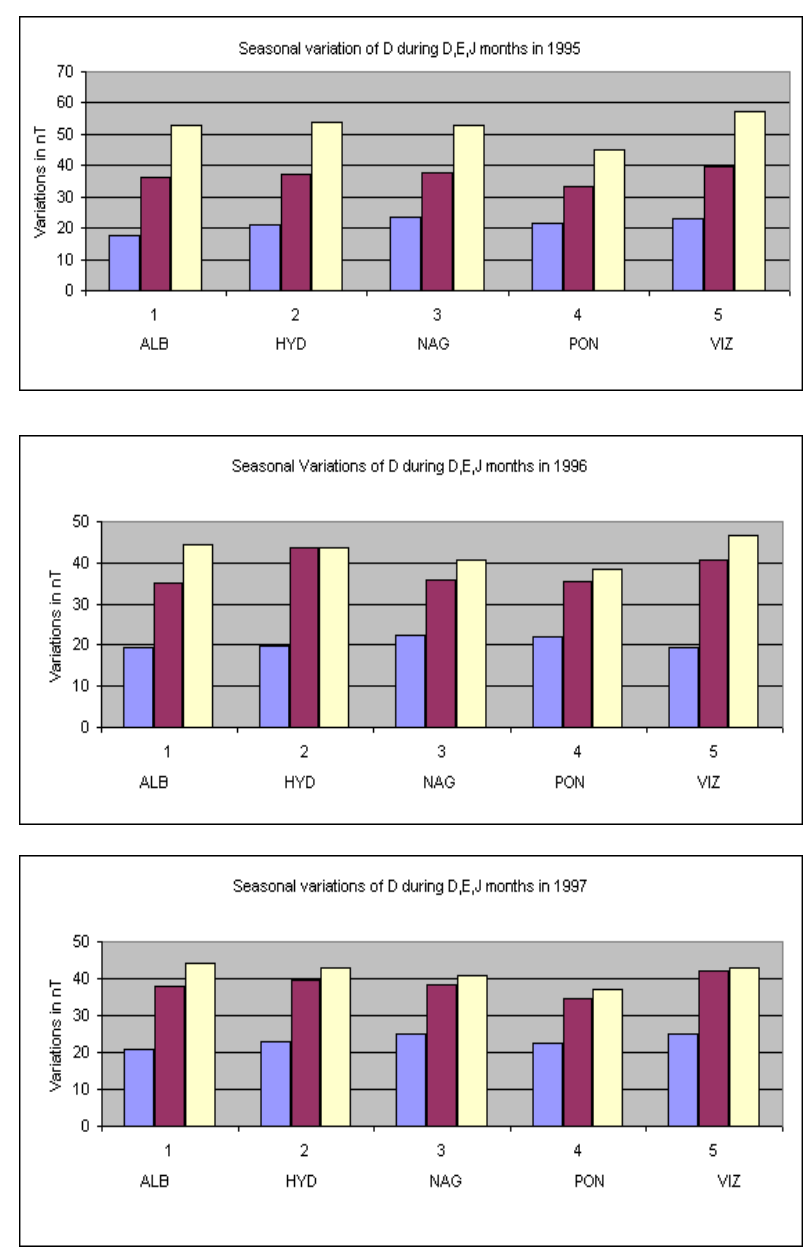

Fig. 1. Seasonal variations of the declination D-component during $\mathrm{D}, \mathrm{E}, \mathrm{J}$ months.
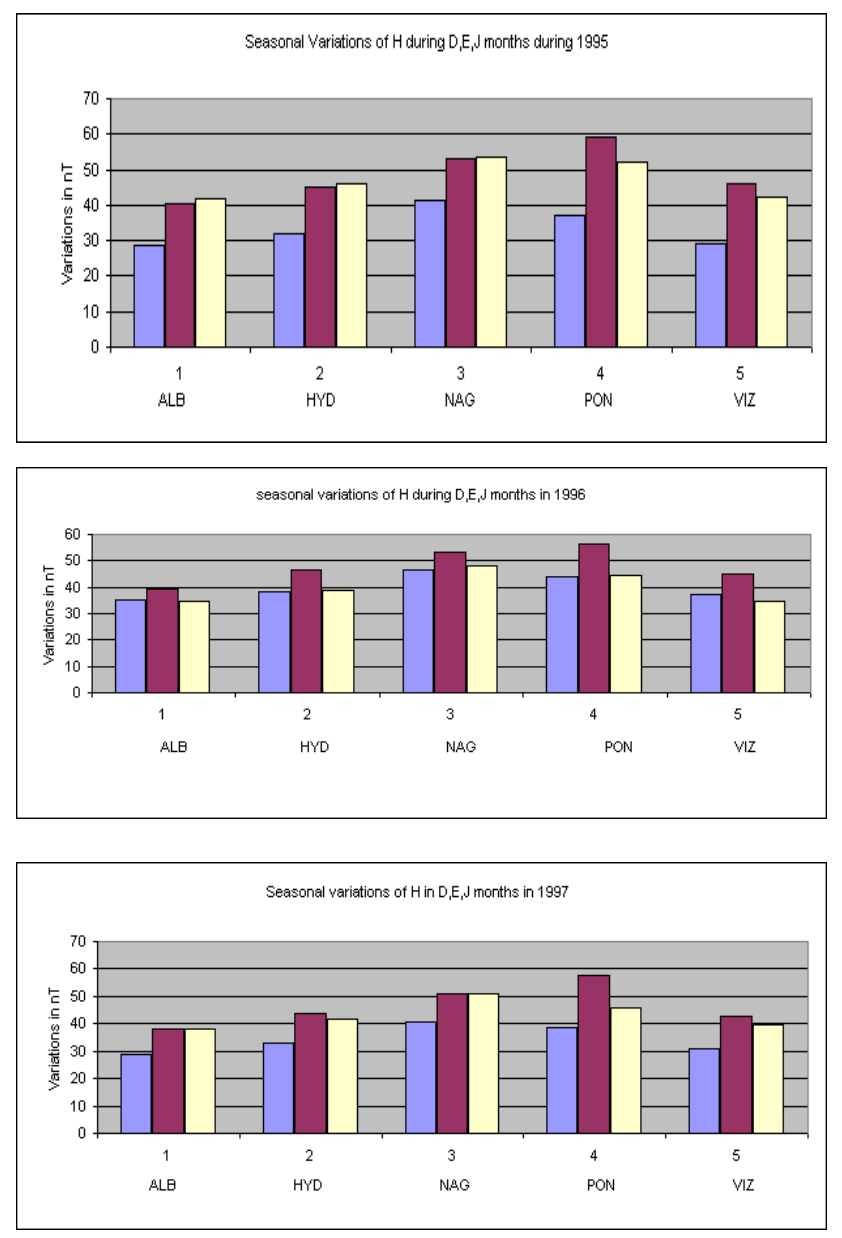

Fig. 2. Seasonal variations of the horizontal H-component during D, E, J months. 
Using the transitive algorithm, $\mathrm{R}^{(4)}$ is obtained as follows:

$\mathrm{R}^{(4)}=\mathrm{R}^{(2)} \mathrm{o} \mathrm{R}^{(2)}=$

\begin{tabular}{|c|c|c|c|c|c|}
\hline & ALB & HYD & NAG & PON & VIZ \\
\hline ALB & 1 & 0.60323 & 0.59885 & 0.41220 & 0.57026 \\
\hline HYD & 0.60323 & 1 & 0.59855 & 0.41220 & 0.57026 \\
\hline NAG & 0.59855 & 0.59855 & 1 & 0.41220 & 0.57026 \\
\hline PON & 0.41220 & 0.41220 & 0.41220 & 1 & 0.41220 \\
\hline VIZ & 0.57026 & 0.57026 & 0.57026 & 0.41220 & 1 \\
\hline
\end{tabular}

Again using the transitive algorithm, $\mathrm{R}^{(8)}$ is obtained as follows:

$\mathrm{R}^{(8)}=\mathrm{R}^{(4)} \mathrm{o} \mathrm{R}^{(4)}=$

\begin{tabular}{|c|c|c|c|c|c|}
\hline & ALB & HYD & NAG & PON & VIZ \\
\hline ALB & 1 & 0.60323 & 0.59885 & 0.41220 & 0.57026 \\
\hline HYD & 0.60323 & 1 & 0.59855 & 0.41220 & 0.57026 \\
\hline NAG & 0.59855 & 0.59855 & 1 & 0.41220 & 0.57026 \\
\hline PON & 0.41220 & 0.41220 & 0.41220 & 1 & 0.41220 \\
\hline VIZ & 0.57026 & 0.57026 & 0.57026 & 0.41220 & 1 \\
\hline
\end{tabular}

Next it is observed that

$\mathrm{R}^{(8)}=\mathrm{R}^{(4)} \mathrm{o} \mathrm{R}^{(4)}$

$=\mathrm{R}^{(4)}$

and $\mathrm{R}^{(16)}=\mathrm{R}^{(8)}$ o $\mathrm{R}^{(8)}$

$=\mathrm{R}^{(4)} \mathrm{o} \mathrm{R}^{(4)}$

$=\mathrm{R}^{(4)}$, etc. $\ldots$

Consequently, no new matrix is obtained after $\mathrm{R}^{(8)}$. This indicates that the stopping condition for the algorithm has been reached. As a result, the final matrix $R \tau$ is taken as $R^{(8)}$. The transitive closure of $\mathrm{R}$ is taken as $\mathrm{R}^{(8)}$ (Friedman and Kandel, 1999).

\section{Dendogram}

The result of single linkage clustering (Maskay, 1998) is displayed graphically in the form of a diagram called dendogram (Everstt, 1985). The term "dendogram" is used in numerical taxonomy for any graphical drawing or diagram giving a tree-like description of a taxonomic system. More generally, Calinski (1988) describes a dendogram as a 2-D diagram representing a tree of relationships, whatever their nature. The representation of a taxonomic system by a dendogram is particularly suitable in connection with a cluster analysis, to investigate the structure of the corresponding operational taxonomic units, that is, entities or individuals considered as the lowest-ranking taxa within the system.
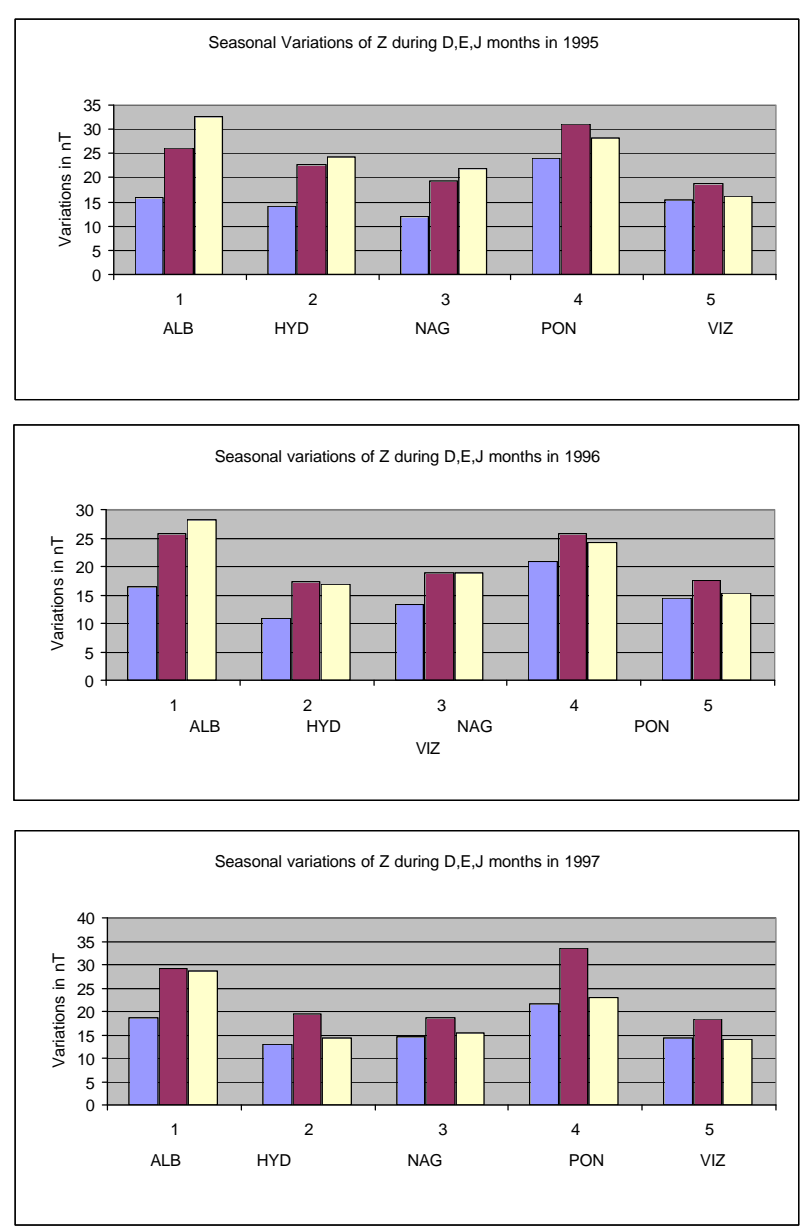

Fig. 3. Seasonal variations of the vertical Z-component during D, E, J months.

From the above table $\mathrm{R}^{(8)}$, it is observed that the transitive closure leads to the cuts in the interval $[0,1]$ at 0.60323 , $0.59855,0.57026,0.41220$, as shown below.

$\alpha$-cuts:

$0--\ldots 0---\ldots---0----0---0---0---\ldots,---0---\ldots---0---$

$\begin{array}{llllll}0 & 0.60323 & 0.59855 & 0.57026 & 0.41220 & 1\end{array}$

Thus, the following $\alpha$-cuts are formed by $\mathrm{R} \tau$

$\alpha \in(0.60323,1] \quad:\{(\mathrm{ALB}),(\mathrm{HYD}),(\mathrm{NAG}),(\mathrm{PON}),(\mathrm{VIZ})\}$

$\alpha \in(0.59855,0.60323]:\{(\mathrm{HYD}, \mathrm{ALB}), \mathrm{NAG}, \mathrm{PON}, \mathrm{VIZ}\}$

$\alpha \in(0.57026,0.59855]:\{(\mathrm{HYD}, \mathrm{NAG}),(\mathrm{NAG}, \mathrm{ALB}),(\mathrm{ALB}, \mathrm{NAG})\}$

$:\{(\mathrm{HYD}, \mathrm{ALB}, \mathrm{NAG}),(\mathrm{PON}),(\mathrm{VIZ})\}$

$\alpha \in(0.41220,0.57026):\{(\mathrm{ALB}, \mathrm{VIZ}),(\mathrm{HYD}, \mathrm{VIZ}),(\mathrm{NAG}, \mathrm{VIZ})$,

(VIZ, ALB)\}

: [(HYD, ALB, NAG, VIZ), PON]

The $\alpha$-cuts are considered one-by-one, starting from the right-hand side and moving in the left direction. The first $\alpha$-cut to be considered is $(0.60323,1]$. 


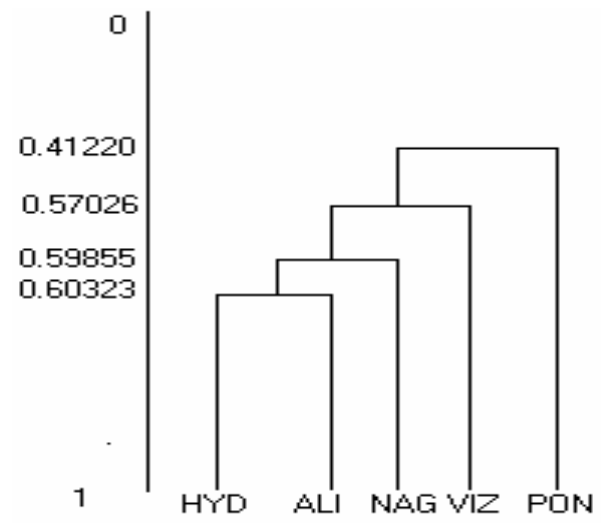

Fig. 4. Dendogram for declination D-component.

The entries in the $R^{(8)}$ which are greater than 0.60323 and less than or equal to 1 are $1,1,1,1,1$. These values correspond to the pairs ALB-ALB, HYD-HYD, NAG-NAG, PON-PON, VIZ-VIZ. Thus, corresponding to the first $\alpha$ cut $(0.60323,1)$, each one of the five stations, namely ALB, HYD, NAG, PON and VIZ, form a distinct partition.

The next $\alpha$-cut has to be considered by moving from the right end of the interval to the left. Thus, one has to consider the $\alpha$-cut $(0.59855,0.60323)$. The entries which are greater than 0.59855 and less than or equal to 0.60323 correspond to the pairs HYD-ALB. Consequently, it is concluded that the pair HYD-ALB forms a cluster corresponding to the $\alpha$-cut $(0.59855,0.60323)$.

Next, the $\alpha$-cut $(0.57026,0.59855)$ is taken up for consideration. The pairs associated with this $\alpha$-cut are HYDNAG, NAG-ALB, and ALB-NAG. Therefore, HYD, ALB and NAG form a cluster and PON and VIZ are isolated.

Next, the $\alpha$-cut $(0.41220,0.57026)$ is taken up for consideration. Here VIZ joins with the last cluster and PON is isolated.

The first cluster in the dendogram for the declination component D (Fig. 4) indicates that HYD and ALB have similar characteristics in terms of its variations in the declination component. It is also seen from this figure that the variations in the declination component for PON stand apart from the cluster.

By applying the same procedures, the values of $\mathrm{R} \tau$, which induces the following partition for its $\alpha$-cuts for horizontal component $\mathrm{H}$ and vertical component $\mathrm{Z}$, are found. The details are shown for component $\mathrm{D}$ and are similar for the $\mathrm{H}$ and Z-components.

For the horizontal $\mathrm{H}$-component $\mathrm{R} \tau$ induces the following four partitions for its $\alpha$-cuts:

$$
\begin{aligned}
\alpha \in(0.79247,1] & :\{(\text { ALB }),(\mathrm{HYD}),(\mathrm{PON}),(\mathrm{NAG}),(\mathrm{VIZ})] \\
\alpha \in(0.69268,0.79247] & :\{(\mathrm{VIZ}, \mathrm{HYD}), \mathrm{ALB}, \mathrm{PON}, \mathrm{NAG}, \mathrm{VIZ}] \\
\alpha \in(0.53951,0.69268] & :\{(\mathrm{ALB}, \mathrm{HYD}),(\mathrm{ALB}, \mathrm{VIZ})\} \\
& :\{(\mathrm{ALB}, \mathrm{HYD}, \mathrm{VIZ}), \mathrm{PON}, \mathrm{NAG}\} \\
\alpha \in(0.39213,0.53951] & :\{(\mathrm{NAG}, \mathrm{PON})] \\
& :[(\mathrm{ALB}, \mathrm{HYD}, \mathrm{VIZ}),\{\mathrm{PON}, \mathrm{NAG}\}] .
\end{aligned}
$$

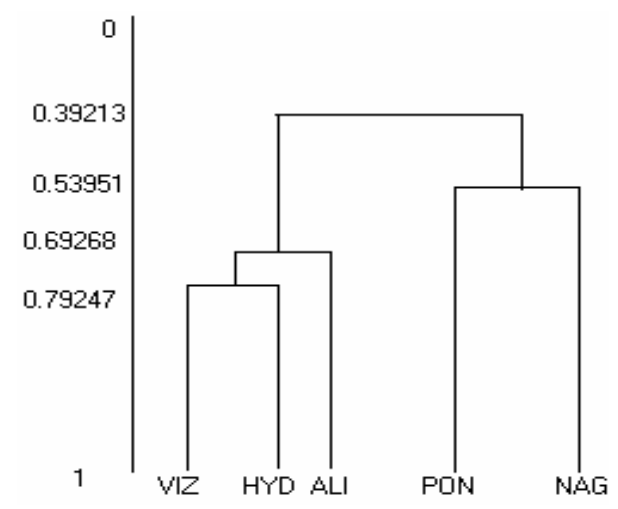

Fig. 5. Dendogram for horizontal H-component.

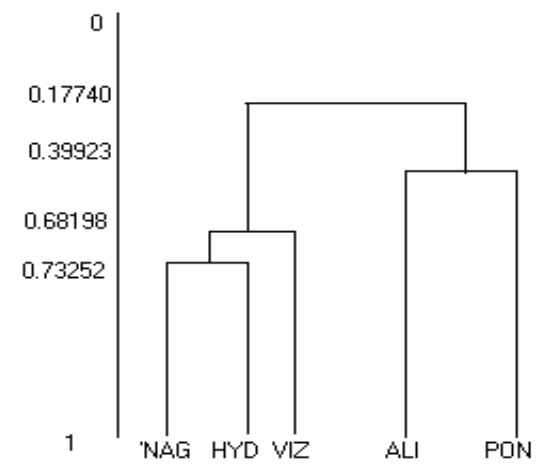

Fig. 6. Dendogram for vertical Z Component.

The dendogram for the horizontal component $\mathrm{H}$ (Fig. 5) indicates that the variations in $\mathrm{H}$ for the stations VIZ and HYD form a cluster, and ALB joins VIZ in the cluster, and PON and NAG stand apart from the first cluster.

For the vertical $\mathrm{Z}$-component $\mathrm{R} \tau$ induces the following four partitions for its $\alpha$-cuts:

$$
\begin{array}{ll}
\alpha \in(0.73252,1] & :\{(\mathrm{ALB}),(\mathrm{HYD}),(\mathrm{NAG}),(\mathrm{VIZ})] \\
\alpha \in(0.68198,0.73252]:\{(\mathrm{NAG}, \mathrm{HYD}), \mathrm{ALB}, \mathrm{PON}, \mathrm{VIZ}] \\
\alpha \in(0.39923,0.68198]:\{(\mathrm{HYD}, \mathrm{NAG}, \mathrm{VIZ}), \mathrm{ALB}, \mathrm{PON}] \\
\alpha \in(0.17740,0.39923]:[(\mathrm{HYD}, \mathrm{NAG}, \mathrm{VIZ}),(\mathrm{ALB}, \mathrm{PON})] .
\end{array}
$$

The dendogram for the vertical component $Z$ (Fig. 6) indicates that the variations in $\mathrm{Z}$ for the stations NAG and HYD, central inland stations, form a cluster, and VIZ joins the first cluster, and ALB and PON stand apart from the first cluster and form a different cluster.

\section{Findings of the study}

Seasonal variations of $\mathrm{D}, \mathrm{H}$ and $\mathrm{Z}$ in Table 3 are plotted (Figs. 1, 2, 3) for all the stations for the years 1995 to 1997 and they are compared.

Fuzzy clustering has been achieved with continuous data from the 36 months listed in Table 2, for each component separately, to study the overall pattern and proximity of one 
observatory to the other. Seasonal variation of the individual observatories forms the same pattern for all 3 years.

An examination of Figs. 1, 2, and 3 - in comparison with the respective dendograms (Figs. 4, 5 and 6) show the following:

- Of the $\mathrm{Sq}(\mathrm{D})$ ranges observed among the 5 stations, ALB and HYD show the same range of variations, NAG and VIZ show marginally enhanced variations and PON stands apart. The dendogram of $\mathrm{D}$ agrees with this result.

- The $\mathrm{Sq}(\mathrm{H})$ range of values at ALB is less compared to HYD but no definite trend emerges at VIZ. The $\mathrm{Sq}(\mathrm{H})$ range for VIZ is comparable to HYD. The results of Srivastava et al. (2001) agree with this present study. NAG and PON values are high compared to the other three places in all seasons. This result has also been established with the Fuzzy clustering technique. NAG and PON form a separate cluster VIZ, HYD and ALB form a separate cluster which results in the dendogram for $\mathrm{H}$ variations.

- Sq(Z) range values at ALB and PON are high compared to HYD for all three seasons. Sq(Z) values at VIZ are less compared to HYD, except in summer months. NAG and HYD, which are far away from either of the coasts, are nearer to each other in variations of the vertical component. The dendogram for Z-variations confirms the result.

It is necessary to recollect the findings of Srivastava et al. (2001) that vast deposits of limestone have been discovered in the Bay of Bengal off Visakhapatnam and that a relatively deep resistive body may not allow the (Sq)-induced currents in the seawater to concentrate near the Visakhapatnam coast. In the case of Alibag on the west coast, however, such induced (Sq) currents in the Arabian Sea do concentrate along the coast line and the continental margins give rise to an enhanced daily range in $\mathrm{Z}$ and reduced daily ranges in $\mathrm{H}$ and $\mathrm{D}$, as compared to those at the Hyderabad station.

Although PON and VIZ are in the same coastal region only ALB and PON form the same pattern. An examination of the graphical plots and dendogram for $\mathrm{Z}$ reveal this fact.

\section{Conclusion}

The application of fuzzy concepts for pattern recognition and classification have been used for numerous applications in astronomy, meteorology, geology for planetary exploration, terrestrial geologic feature analysis, cartography and geodesy, surface model fittings, satellite data analysis, artificial intelligence, etc. This technique is used here to study the identical pattern of geomagnetic variations at Indian observatories. Generally, for a huge volume of data in a complicated analysis this technique yields accurate results. As a result of this study, it is expected that future usage of this technique may be appropriate for exploring some new results in geomagnetism.

Acknowledgements. The authors are very grateful to the two referees whose painstaking and critical evaluation of the first version of the manuscript has greatly improved the quality of presentation.

Topical Editor U.-P. Hoppe thanks two referees for their help in evaluating this paper.

\section{References}

Anderberg, M. R.: Cluster analysis for applications, Academic Press, New York, 1973.

Bhargava, B. N and Rangarajan, G. K.: Solar Control of low latitude quiet-day magnetic field, Proc. Indian Acad. Sci., 93-100, July 1979.

Bhargava, B. N. and Yacob, A.: Solar cycle response in the horizontal force of the earth's magnetic field, Journal of Geomagnetism and Geo electricity, 21, 1, 385-397, 1969.

Bhargava, B. N. and Yacob, A.: Local time and solar cycle features of day-to-day variability in geomagnetic horizontal intensity, Ann. Geophys., 30, 487-492, 1974.

Calinski, T.: Encyclopaedia Biostatistics, in: Dendogram in Encyclopaedia Biostatistics, edited by: Armitage,P. and Cotton, T., 2 , 1131-1132, 1988.

Campbell, H.: Introduction to Geomagnetic field, Cambridge University Press, UK, 67, 1997.

Everstt, B.: Cluster analysis, John Wiley and Sons, New York, 1985.

Friedman, M. and Kandel, A.: Introduction to Pattern RecognitionStatistical, Structural, Neural and Fuzzy Logic Approaches, Imperial College Press, London SW72BT, 1999.

Klir, G. J. and Yuvan, B.: Fuzzy sets and Fuzzy Logic, theory and applications, Prentice Hall of India Private Ltd., N. New Delhi, 1997.

Klir, G. J. and Folger, T. A.: Fuzzy sets, uncertainty and information, Prentiece Hall of India Private Ltd, New Delhi, 2000.

Maskay, N.: Single linkage clustering in: Armintage. P and Colton, T.: Encyclopedia of Bio-Statistics, Wiley, New York, 5, 41214122, 1998.

Parkinson, W. D.: Introduction to Geomagnetism, Scottish Academic Press, Edinburgh and London, 1983.

Rangarajan, G. K.: Daily variation of geomagnetic field at low latitudes associated with stable solar wind flow. Proc. Indian Acad. Sci. March 1981, 55-62, 1981.

Rangarajan, G. K.: "Best" estimates of the amplitude of diurnal and Semidiurnal Components of $\mathrm{Sq}(\mathrm{H})$ and their annual variations, Indian Journal of Radio and Space Physics, 4, 46-49, 1975.

Rastogi, R. G. and Patil, A. R.: On Certain Aspects of Daily Variation of Geomagnetic Field at Low Latitudes, J. Geomag. Geoelectr., 44, 495-503, 1992.

Srivastava, B. J., Habiba Abbas, Rama Gopal, T., Rao, D. R. K. and Pahtan, B. M.: Geomagnetic coast and other effects deduced from the new observatory at Visakhapatnam, India, Geophys. J. Int. 146, 827-832, 2001.

Yacob, A. and Sen, A. K.: On quiet day Maximum and Minimum range in H, Pure and applied Geophysics, 112/2, 464-471, 1974.

Yacob, A.: Latitudinal profile in India of $S_{q}(\mathrm{H})$ range and of its prominent periodicities, Pageoph, 113, 601-609., 1975.

Zadeh, L. A.: Fuzzy sets, Information and Control, 8, 338-353, 1965. 